\title{
“ESCRITORES DA LIBERDADE”: UMA ANÁLISE A PARTIR DA TEORIA DE PICHON- RIVIÈRE
}

Rosana Vera de Oliveira Schicotti, Gelise Soares Alfena, Valteir Carvalho Freitas

Universidade do Oeste Paulista - UNOESTE, Presidente Prudente, SP. E-mail: rosanavera@unoeste.br

\section{RESUMO}

O objetivo precípuo deste trabalho é analisar o filme "Escritores da Liberdade" à luz da teoria de Pichon-Rivière, com base no método psicanalítico, cujo caráter é interpretativo, na medida em que é construído em um processo de atribuição de sentidos. Para tanto, elegemos aspectos da obra referentes ao trabalho com grupos e os interpretamos de modo a discutir o processo de ensino-aprendizagem, bem como o papel do coordenador (neste caso específico, uma professora e sua importância para a transformação de realidades vulneráveis e desfavorecidas socialmente). A partir desta análise, pudemos discutir e esclarecer a relevância do manejo e do conhecimento dos processos grupais para a promoção do conhecimento e da interação professor-aluno.

Palavras-chave: processos grupais; ensino-aprendizagem; relação professor-aluno; interação; sala de aula.

\section{"FREEDOM WRITERS": AN ANALYSIS FROM THE THEORY OF PICHON-RIVIERE}

\begin{abstract}
The main objective of this study is to analyze the film "Freedom Writers" in view of PichonRivière's theory, based on the psychoanalytic method, whose nature is interpretive, as far as it is built on a process of assigning meanings. Therefore, we have selected aspects of the work related to the group work and we have interpreted them in order to discuss the teaching-learning process, as well as the coordinator's role (in this particular case, a teacher and her importance to the changing of vulnerable and socially disadvantaged realities). From this analysis, we were able to discuss and clarify the relevance of management and knowledge of group processes for fostering knowledge and teacher-student relationship.
\end{abstract}

Keywords: group processes; teaching-learning; teacher-student relationship; interaction, classroom. 
INTRODUÇÃO

O filme "Escritores da Liberdade" é baseado em uma história real, mais especificamente no livro de nome "Diário dos Escritores da Liberdade", escrito pelos alunos da sala 203 do colégio Woodrow Wilson, Califórnia, produzido pela Paramount Pictures, em associação com a MTV Films, lançado no ano de 2007 e dirigido por Richard LaGravenese. O filme conta a vivência de uma professora de Língua Inglesa e Literatura, Erin Gruwell, e suas experiências com os alunos designados incapazes. Isso se dá porque, naquela época, era instalado nos EUA, um programa de integração voluntária que abriu as portas das escolas para os adolescentes que constituíam as "minorias raciais", ou seja, os imigrantes, afro-descentes, latinos e orientais. Porém, estes não foram realmente integrados e, por isso, eram segregados dos estudantes "Notáveis e Especiais", os brancos e ricos. A diferenciação entre os dois grupos de estudantes era tão grande que o ensino designado ao grupo estigmatizado era de baixa qualidade.

Em meio a esse território de separações e preconceitos, surge essa professora branca que, inicialmente, é recebida como inimiga deles. Erin trilhou um caminho assaz árduo, todavia adquiriu conhecimento e conseguiu realizar uma mudança de comportamento e de vida em uma instituição extremamente adoecida e, principalmente, num contexto social violento e marcado por dores. Ela escolheu fazê-lo, empenhou-se, mesmo sabendo que, em certo momento, teria que fazer algumas difíceis escolhas, comprometendo, assim, sua vida pessoal.

O papel exercido pela professora, na obra, é semelhante ao papel do coordenador de um grupo operativo, pois cabe a ela sinalizar as dificuldades que impedem o grupo de enfrentar a tarefa e as ansiedades básicas (medo da perda e do ataque), propor hipóteses que permitam aos membros aprimorar o autoconhecimento e favorecer a comunicação e a aprendizagem, resolver discussões frontais que são frutos de um modo de ver e pensar rígidos, procurar dar início ao processo de criar, manter e fomentar a comunicação, mobilizar estruturas estereotipadas quanto ao objetivo do grupo e possibilitar o surgimento de conhecimentos que instrumentalizem as ações do grupo no nível individual e grupal (PICHON-RIVIÈRE, 2009).

Dito de outro modo, é importante esclarecer que o grupo operativo, segundo a definição de Enrique J. Pichon-Rivière, pode ser compreendido como um conjunto de pessoas com um objetivo comum. Os grupos operativos são centrados na tarefa que se caracteriza por uma intenção, um objetivo, aquisição de conhecimento e aprendizagem, podendo apresentar heterogeneidade quanto à sua composição, mas devendo apresentar homogeneidade quanto à tarefa (PICHON-RIVIÈRE, 1988). O grupo, na referida obra cinematográfica, é composto por uma variedade étnica, entretanto o que os une, de fato, é o contexto violento e a história de vida 
marcada por acontecimentos trágicos, prisões e assassinatos de seus entes queridos. O objetivo da professora centra-se na aprendizagem e no conhecimento, embora a maioria dos integrantes do grupo não achasse que isso seria possível de fato.

A professora Erin Gruwell depara-se com uma sala discriminada, cheia de alunos considerados problemáticos, envolvidos com gangues, portadores de um comportamento hostil, resistência, falta de interesse e de esperança, com discursos sem perspectiva de futuro e de mudança de situação. Essa situação exemplifica o que Pichon-Rivière (2009) postula quando afirma que é no momento denominado pré-tarefa (primeiros contatos, o momento que antecede a tarefa) que surge a resistência à mudança e a dissociação do sentir, pensar e agir. Este é o momento em que o coordenador deve se atentar para a existência de modelos fechados, modelos abertos e modelos transitórios de pensar sobre o mundo que, juntamente com a estereotipia, podem vir a tornarem-se rígidos pela ansiedade que está mobilizada no grupo.

Desta forma, partindo destes pressupostos, pretendemos, neste trabalho, tecer uma análise do filme "Escritores da Liberdade" à luz da teoria de Pichon-Rivière. Em outras palavras, objetivamos relacionar alguns dos conceitos e modos de funcionamento propostos pelo autor supracitado no que tange aos processos grupais e, ainda, verificar como acontece o processo de ensino/aprendizagem nessa perspectiva.

\section{METODOLOGIA}

Pretendemos, neste artigo, analisar o filme "Escritores da Liberdade", usando o referencial teórico-metodológico de Pichon-Rivière, no que se refere aos processos grupais. Esse autor iniciou suas investigações sobre os grupos operativos a partir de uma experiência realizada em 1958, denominada Experiência Rosário. Tal experiência esteve sob a responsabilidade do Instituto Argentino de Estudios Sociales (IADES) e foi planificada e dirigida por Enrique Pichon-Rivière. $\mathrm{O}$ referido autor trabalhou com o método e a didática interdisciplinar, a qual é acumulativa, interdepartamental e de ensino orientado.

Essa perspectiva metodológica pressupõe o caráter dialético da interação entre indivíduo e sociedade, baseando-se também na teoria do vínculo, definida como uma estrutura triangular:

[...] que rege todas as nossas relações, possibilita abandonar o esquema de uma psicologia individual, que Freud já negava, e adotar os postulados de uma psicologia que sempre será social, ao incluir no esquema de referência o conceito de um mundo interno em contínua interação, origem das fantasias inconscientes (PICHON-RIVIÈRE, 2009, p.162). 
Podemos perceber que dentro da perspectiva interdisciplinar e dialética de Pichon-Rivière encontra-se a influência da psicanálise. Segundo Herrmann (2004, p.61), a psicanálise é a ciência da psique que se "[...] ocupa em investigar o sentido humano, nas pessoas - nos pacientes em particular -, nos grupos e organizações dos homens, na sociedade e em suas produções culturais". Assim, levando em conta que a obra cinematográfica "Escritores da Liberdade" é uma produção cultural, buscaremos compreendê-la e analisá-la também a partir da psicanálise, neste enquadre, o conhecimento/a pesquisa tem um caráter interpretativo, na medida em que é construído em um processo de atribuição de sentidos.

Nesse sentido, inspirados em Pichon-Rivière e fundamentados na teoria/método psicanalítico, buscamos compreender o filme "Escritores da Liberdade" com o objetivo de desvelar os processos grupais envolvidos, a relação professor-aluno e suas conexões com a cultura e os fenômenos inconscientes.

\section{RESULTADOS}

O ponto inicial do processo de aproximação/vínculo da professora com os alunos gira em torno do discurso que ela faz ao se deparar com uma folha de papel que estava circulando pela sala. Nela, estava a caricatura de um dos alunos negros, enfatizando seus lábios grandes, motivo pelo qual os colegas o ridicularizaram. Erin, a professora, então, compara a atual situação vivenciada em sala de aula, ao momento histórico do Holocausto, ambos representados pela intolerância direcionada ao próximo. Após uma breve discussão em sala de aula acerca desse tema, um dos alunos dirige-se à professora dizendo que ela não entende a realidade vivida por eles, alegando a diferença racial e social entre ela e seus alunos. Diante disso, Pichon-Rivière (1988) descreve, em um primeiro momento do trabalho com grupos, que há um movimento de grande resistência frente às supostas mudanças, o que ocorre devido à existência do medo, isto é, o medo do novo, do desconhecido, de sair de uma zona de conforto já existente. Ainda, Bleger (1998) afirma que o processo de ensino e aprendizagem deve ocorrer ao mesmo tempo, alertando para o risco da ansiedade diante da mudança não se tornar uma forma de bloqueio do ensino e consequentemente de alienação do ser humano.

O fato que é mostrado na primeira discussão, sobre o Holocausto, serve para aproximar ambas as realidades, quebrar as resistências e persecutoriedades (sentimento de perseguição) existentes no grupo. Segundo Zimerman (2004), a persecutoriedade existente, ou mesmo sua sensação, seria um tipo de defesa contra o medo internalizado que se manifesta de forma agressiva por meio de condutas de autossuficiência, atitudes rígidas e estereotipadas. Quanto à 
estereotipia, há algo fundamental que Bleger (1998) enfatiza quanto ao ensino grupal, que se encaixa na análise desta obra: o fato de que se deve partir da indagação para elucidar algo que ainda não está claro, pois, assim, contribui-se para a ruptura de estereótipos que não permitem que o trabalho avance.

Em crítica ao intelectualismo que contamina o conceito de aprendizagem, Bleger (1998) define o conceito de aprender como uma modificação de caráter, mais ou menos estável, em qualquer área, mesmo que não ocorra uma formulação intelectual. Essa afirmação pode ser exemplificada por dois fatos no filme: a discussão sobre o holocausto que parte da caricatura em sala de aula, e quando a professora começa a trazer histórias e situações ocorridas pelo mundo afora, fazendo ligação com situações da realidade que vivem. Com estas duas ações, a professora começa a introduzir, em sala, um mundo que vai além do contexto da realidade violenta e da vivência com as gangues. Tal processo torna-se mais eficaz quando ela incentiva a leitura de livros, decide levá-los para visitar um museu e conhecer histórias de sobreviventes da guerra.

Quanto ao individual e o coletivo dentro dos grupos, há um processo de construção que gera uma história própria, e dá ao grupo especificidade e identidade que se faz na relação de dois contextos (PICHON-RIVIÈRE, 1988): o primeiro, ele denomina de verticalidade, isto é, aquilo que se relaciona com a história pessoal consciente e inconsciente do indivíduo. A partir do momento que os membros do grupo passam a compartilhar objetivos comuns, criam uma nova história que não se pode dizer que é somente a junção das histórias individuais (verticalidades), pois esta surge a partir da interação dos indivíduos, o que gera a horizontalidade, ou seja, a história do grupo, com suas especificidades e identidade grupal (BASTOS, 2010). Desse modo, vemos que ora os sujeitos sentem-se influenciados pela sua verticalidade, ora pela horizontalidade, em um movimento dialético.

No início de trabalho em sala de aula, percebe-se a presença de vínculos paranoicos (caracterizando-se pela desconfiança e hostilidade mútuos) resultantes do modo com que o indivíduo se relaciona com o objeto (PICHON-RIVIÈRE, 1988). Segundo Bleger (1998), o momento paranoico caracteriza-se pela atitude de hostilidade ou desconfiança frente à descoberta do objeto. As atitudes da personagem Eva, no início da obra, podem exemplificar esse modo de funcionamento.

Quanto à tarefa (a aprendizagem), há nitidamente alunos que veem e vivenciam o grupo de maneira indiferente, pois realmente acreditam que tudo que fazem em sala não tem nenhuma importância para suas vidas, apresentando como característica uma maior resistência a tudo que se propõe (atividades, diálogos e leituras). Essa forma de pensar e agir está ligada ao início do 
trabalho da professora e, segundo Pichon-Rivière (2009), é o momento em que aparecem as diferenças individuais, as mudanças internas e externas que o aprendizado provoca, as reações de aceitação e de repúdio e, ainda, que cada um atribui um significado ao grupo. O fenômeno da transferência também acontece na relação professor-aluno e aparece nas relações de amor e ódio dos alunos da sala 203 para com a professora Erin. A transferência de acordo com Herrmann, em entrevista realizada por Lino da Silva (1993), pode ser compreendida como reedições de experiências psíquicas do paciente para a figura do analista, não se confina apenas ao setting analítico, mas pode ser evocada em uma pesquisa e aparece em diferentes configurações psíquicas/sociais.

\section{DISCUSSÃO}

A mudança de estratégia diante das dificuldades encontradas no início do trabalho em sala de aula sai do método expositivo para algo que consiga chamar a atenção dos alunos, em virtude do desinteresse e da insatisfação demonstrados pelos mesmos. Tal mudança configura-se numa tentativa de criar o que Pichon-Rivière (1988) postula como tele (termo usado por Moreno, criador do Psicodrama, que designa a capacidade de diferenciar o "eu" do "outro"), todavia de forma positiva, tentando despertar o sentimento de empatia, isto é, de se colocar no lugar do outro e desenvolver um clima que cause atração quanto às tarefas. Bleger (1998) vai além e nos ajuda a entender os resultados positivos obtidos por essa mudança, quando tece nova crítica, agora aos sistemas educativos e pedagógicos, afirmando que métodos antiquados de ensino resultam da luta de interesses das classes sociais que moldaram esses sistemas e são instrumentos de bloqueio e controle.

Ainda no início do filme, fato que se torna fundamental para a professora, é a compreensão da história daquele grupo, entender que por detrás de cada frase de agressão ou ato de resistência existe algo que precisa ser dito sobre a realidade individual. Por meio de tais comportamentos, os alunos trazem materiais que podem ser trabalhados naquele ambiente. Dessa forma, o jovem Jamal torna-se o porta-voz (termo utilizado por Pichon-Rivière) do grupo, pois, dentre todos, é o membro que se expressa como se fosse algo seu o que até então estava latente ou implícito ao grupo (PICHON-RIVIÈRE, 2009). Falar é um dos aspectos que facilitam a comunicação em um nível mais integrado, porém tomando-se cuidado para que a linguagem não paralise o grupo, sendo que este falar pode ser especializado por um membro do grupo e, além disso, contém uma função específica que deve ser analisada cuidadosamente para que não cause perturbações na comunicação (BLEGER, 1998). 
O fato que exemplifica essa ideia é o momento em que um dos alunos, Tito, pede para conhecer mais a respeito do holocausto. Assim, o estereótipo de intolerância começa a ser quebrado, tanto no plano individual quanto no grupal. A partir deste momento, pelo efeito emocional e reflexivo provocado nos alunos e o interesse demonstrado no conteúdo desta discussão, a professora começa a trazer dinâmicas para a sala, pois, apesar de certa interação existente, a comunicação ainda ocorria precariamente.

Na primeira dinâmica realizada com os alunos, a professora cola uma fita vermelha no meio da sala e divide o grupo ao meio. Os alunos ficam a certa distância da fita e a professora faz perguntas comuns ao cotidiano de cada um deles. Quando a pergunta apresenta resposta afirmativa, o aluno pisa na fita vermelha, quando não, o aluno permanece no mesmo lugar. Ao final, muitos deles acabam descobrindo que têm muitas afinidades. Muito prematuramente, percebe-se que a dinâmica pode dar início a um dos mecanismos que devem estar presentes no grupo que Pichon-Rivière (2009) caracteriza como cooperação, que é a troca de informação entre os participantes do grupo, ou seja, aquilo que os membros trazem de si para o grupo, contribuindo para a tarefa.

Propõe-se outra atividade aos alunos: estes deverão escrever em um diário sobre qualquer assunto que Ihes interesse, desde fatos sobre o seu cotidiano até segredos de sua vida. A professora passa a deixá-los livres para que decidam se querem ou não escrever. Além disso, aqueles que escreverem e desejarem que ela leia, colocarão o seu diário em um armário no fundo da sala. Ao escreverem sobre si, há uma associação da maneira de agir com os sentimentos experimentados durante as situações, quando estes justificam suas ações apenas pelo sofrimento, isentando-se de qualquer tipo de responsabilidade e fugindo de uma possível mudança. Perante isso, Pichon-Rivière (1988) postula haver um movimento grupal baseado no aqui-agora-comigo e também na tarefa do grupo devido à mobilização das estereotipias e do montante de ansiedade.

Esse movimento desperta a possibilidade de mudança e emerge experiências, afetos e conhecimentos com os quais os componentes do grupo valem-se para atuar em nível individual ou grupal. Assim, a história de cada um, revivida dentro do grupo, serve para reflexão e mudança de comportamentos fora dele. As mudanças de atitude dos personagens, ao longo do filme, mostram um processo de vivência grupal que proporciona questionamento e mudança na forma de agir.

Por último, o fator da violência, exercida por eles, pode ter como um dos motivos a escola/instituição. Bleger (1998) afirma que as instituições devem ser problematizadas, pois os conflitos gerados por ela, a escola, implicam na distorção do ensino, pois, se não forem sanados, o estudante pode se tornar um recipiente para estes. 


\section{CONCLUSÃO}

A obra de Pichon-Rivière é muito abrangente no que tange ao trabalho com grupos. Mesmo quando estes não funcionem no modo operativo, como foi postulado por ele, muitos mecanismos manifestam-se de forma semelhante aos pressupostos de sua teoria. Assim, muitas outras obras são passíveis de análise usando esse mesmo referencial teórico.

Percebe-se que é muito comum a mobilização de ansiedades frente à tarefa ou algo novo que surge no grupo. Estimular a comunicação e perceber a que finalidade ela está servindo é de suma importância, visto que só se constrói uma história coletiva (grupal), de fato, quando esta se entrecruza com a história pessoal de cada integrante, mesmo tomando as várias configurações que este possa apresentar.

A instituição e o método de ensino adotado pelo docente contribuem de forma significativa para que o objetivo do ensino/aprendizagem se concretize. Fazer com que os alunos lidem com seus estigmas e estereotipias abrem novas possibilidades de ver e significar o mundo ao seu redor, visto que a aprendizagem aqui é tomada não somente como desenvolvimento intelectual, mas também em sua dimensão terapêutica.

Por fim, deve-se destacar a especificidade do filme "Escritores da Liberdade", no qual foi tomado somente o que aparece e é retratado pelo diretor, sem intenção de criar uma fórmula geral que se estenda a todos os casos em sala de aula ou que traga a teoria do referido autor como único suporte teórico possível. Considera-se a obra analisada como totalmente passível de análise em outras vertentes e linhas teóricas.

\section{REFERÊNCIAS}

BASTOS, A. B. B. I. A técnica de grupos operativos à luz de Pichon-Rivière e Henri Wallon. Psicólogo Informação, ano 14, n. 14, jan/dez 2010. Disponível em <http://www.metodista.br/revistas/revistas-ims/index.php/PINFOR/article/viewFile/2348/2334> acessado: $15 / 08 / 2015$

BLEGER, J. Temas de Psicologia: entrevista e grupos. 2. ed. São Paulo: Martins Fontes, 1998.

HERRMANN, F. Pesquisando com o método psicanalítico. In: HERRMANN, F. \& LOWENKRON, T. (Orgs.). Pesquisando com o método psicanalítico. São Paulo: Casa do Psicólogo, 2004, p.43-121.

LINO DA SILVA, M. E. (Coord.). Investigação e Psicanálise. Campinas - SP: Papirus, 1993.

PICHON-RIVIÈRE, E. Teoria do vínculo. São Paulo: Martins Fontes, 1988.

PICHON-RIVIÈRE, E. O Processo Grupal. 8 ed. São Paulo: WMF Martins Fontes, 2009. 
ZIMERMAN, D. E. Bion: da teoria à prática - Uma leitura didática. 2 ed. Porto Alegre: Artes Médicas, 2004. 